\title{
Simultaneously maximizing root/ mycorrhizal growth and phosphorus uptake by cotton plants by optimizing water and phosphorus management
}

Wenxuan Mai ${ }^{1,24^{*}}$, Xiangrong Xue ${ }^{1,2}$, Gu Feng $^{3}$ and Changyan Tian ${ }^{1,2}$

\begin{abstract}
Background: There are two plant phosphorus (P)-uptake pathways, namely the direct $\mathrm{P}$ uptake by roots and the indirect $P$ uptake through arbuscular mycorrhizal fungi (AMF). Maximizing the efficiency of root and AMF processes associated with $\mathrm{P}$ acquisition by adjusting soil conditions is important for simultaneously ensuring high yields and the efficient use of available $P$.

Results: A root box experiment was conducted in 2015 and 2016. The aim was to investigate the effects of different $P$ and soil water conditions on root/mycorrhizal growth and P uptake by cotton plants. Hyphal growth was induced in well-watered soil, but decreased with increasing P concentrations. Additionally, P fertilizers regulated root length only under well-watered conditions, with the longest roots observed in response to $0.2 \mathrm{~g}$ $\mathrm{P}_{2} \mathrm{O}_{5} \mathrm{~kg}^{-1}$. In contrast, root elongation was essentially unaffected by $\mathrm{P}$ fertilizers under drought conditions. And soil water in general had more significant effects on root and hyphal growth than phosphorus levels. In well-watered soil, the application of $\mathrm{P}$ significantly increased the cotton plant $\mathrm{P}$ uptake, but there were no differences between the effects of 0.2 and $1 \mathrm{~g} \mathrm{P}_{2} \mathrm{O}_{5} \mathrm{~kg}^{-1}$. So optimizing phosphorus inputs and soil water can increase cotton growth and phosphorus uptake by maximizing the efficiency of phosphorus acquisition by roots/mycorrhizae.
\end{abstract}

Conclusions: Soil water and P contents of $19-24 \%$ and $20-25 \mathrm{mg} \mathrm{kg}^{-1}$, respectively, simultaneously maximized root/mycorrhizal growth and P uptake by cotton plants.

Keywords: P uptake, Root, Hyphal density, Cotton

\section{Background}

High inputs and outputs and low nutrient use efficiency are typical characteristics of intensive farming systems in China [1]. For example, to overcome the effects of phosphorus (P)-deficient soils and obtain high crop yields, a large amount of $\mathrm{P}$ fertilizer has been applied to farmlands over the last 20 years, which has resulted in farmland soils having an average P content exceeding $242 \mathrm{~kg} \mathrm{ha}^{-1}$ [2]. However, the efficiency of $\mathrm{P}$ fertilizer use has decreased from 15 to $20 \%$ in the 1990 s to $11.6 \%$ in 2003 [3].

\footnotetext{
* Correspondence: maiwx@ms.xjb.ac.cn

${ }^{1}$ Xinjiang Institute of Ecology and Geography, Chinese Academy of Sciences, Urumqi 830011 , China

${ }^{2}$ State Key Laboratory of Oasis Ecology and Desert Environment, Urumqi 830011, China

Full list of author information is available at the end of the article
}

Considering that $\mathrm{P}$ fertilizers represent a non-renewable resource, improving the efficiency of $\mathrm{P}$ use is of vital importance for ensuring sustainable agricultural production.

Most plants consist of two P-uptake pathways, namely the direct root P-uptake pathway and the arbuscular mycorrhizalfungi (AMF) P-uptake pathway $[4,5]$. Most $\mathrm{P}$ fertilizers are immobilized in soils because $\mathrm{P}$ is strongly adsorbed to iron and aluminum cations at low soil $\mathrm{pH}[6,7]$ and to calcium at high soil $\mathrm{pH}[8]$. This is also the key reason for the low efficiency of $\mathrm{P}$ fertilizer use [9-11]. Thus, root architectural features and the growth of mycorrhizal hyphae are important for maximizing the acquisition of $\mathrm{P}$ because the root and mycorrhizal systems with a relatively high surface area are able to effectively use a given volume of soil [12]. 
Liao et al. [13-15] completed a series of experiments to prove there is a close relationship between bean root architecture and tolerance to low soil P levels. The relatively shallow bean root system is conducive for obtaining $\mathrm{P}$, and provides evidence for the ideal root architecture model. On intensively farmed land, it is unclear whether the AMF P-uptake pathway contributes significantly to crop production. A key reason for this uncertainty is the fact mycorrhizal colonization decreases as the soil P content increases [16]. However, a series of field studies revealed that many AMF are present in high-yielding farmland soil. Moreover, the AMF are associated with a relatively high colonization rate and considerably affect crop $\mathrm{P}$ acquisition from the soil [17]. An investigation involving the ${ }^{32} \mathrm{P}$ isotope confirmed the AMF P-uptake pathway may provide $>20 \%$ of the $\mathrm{P}$ obtained by maize plants, even under conditions of high $\mathrm{P}$ content (i.e., $>50 \mathrm{mg} \mathrm{kg}^{-1}$ according to the Olsen-P method) [18].

Plant root growth is influenced by soil $\mathrm{P}$ and water contents [19]. In many plant species, P deficiency decreases primary root growth and increases the length and density of root hairs and lateral roots [20, 21] to increase the root-soil contact, which will enhance $P$ uptake and the use of the available soil volume [8, 22 ]. The irrigation of crop plants induces significant changes in the growth and distribution of root systems, with important consequences for both nutrient uptake and crop growth. We previously reported that $49 \%$ of the cotton root length is distributed within $10 \mathrm{~cm}$ of the soil surface under drip irrigation conditions, while under flood irrigation conditions, this proportion is only $31 \%$ [23]. There is still some controversy regarding the effects of soil water conditions on AMF [24]. Although most studies have concluded that drought stress can promote the growth of mycorrhizal fungi $[25,26]$, at least one investigation produced contradictory results [27]. Additionally, other studies have indicated that mycorrhizae are unaffected by water conditions, but are influenced by available $\mathrm{P}$ contents in soils $[28,29]$. Therefore, the response of AMF to available soil water is complex, with varying results obtained under diverse experimental conditions. Further research will be needed to clarify these responses.

With gradually decreasing availability of water resources, water-conserving irrigation methods, especially drip irrigation, have been widely promoted for crop production in China. For example, in Xinjiang, which represents a typical arid irrigation area, drip irrigation is used on $>60 \%$ of the cropland, and the proportion continues to increase. However, there has been no change in the method used to apply P fertilizers (i.e., as a base fertilizer), which have accumulated in the soil as in other places in China over the past 30 years. Consequently, maximizing the efficiency of the direct root and AMF P-uptake pathways and optimizing $\mathrm{P}$ nutrient input and soil water conditions are critical for ensuring sustainable high-yielding cotton production. Moreover, because drip irrigation enables the precise management of soil water content, it represents a unique option for improving the efficiency of $\mathrm{P}$ fertilizer use via its effects on root morphology. We hypothesized that the cotton phosphorus uptake can be increased through increasing the growth of cotton roots and mycorrhizal simultaneously by optimizing water and phosphorus management.

The objective of the present study was to determine the effects of $\mathrm{P}$ fertilizers and soil water conditions on the spatial distribution of cotton roots, mycorrhizal fungi growth, and $\mathrm{P}$ uptake by cotton plants. We also aimed to determine the optimal soil $\mathrm{P}$ and water contents for maximizing $\mathrm{P}$ uptake by cotton plants via root-mycorrhizae interactions.

\section{Results \\ Root length and hyphal density}

Cotton roots were longer and grew more deeply into the soil profile under water-limited conditions (Fig. 1a). Moreover, the effect of the $\mathrm{P}$ fertilizer on root elongation depended on the soil water conditions. In well-watered soil, cotton roots were longest $\left(54.1 \mathrm{~m} \mathrm{box}^{-1}\right.$ ) under the P0.2 treatment. In contrast, root length was almost unaffected by $\mathrm{P}$ content under drought conditions.

In all soil layers, the hyphal density under well-watered conditions was higher than that under drought conditions. Additionally, hyphal density decreased with increasing $\mathrm{P}$ content, although the changes were smaller than those induced by different water levels (Fig. 1b). For example, in the $0-10 \mathrm{~cm}$ soil layer, under well-watered conditions, the hyphal densities were 19.7, 19.2, and 18.4 $\mathrm{mg}^{-1}$, while under drought conditions they were 11.8, $8.4,7.8 \mathrm{~m} \mathrm{~g}^{-1}$ in response to the P0, P0.2, and P1 treatments, respectively. The differences in the hyphal densities between the well-watered and drought conditions following the P0, P0.2, and P1 treatments (i.e., 40.1, 52.3, and $57.6 \%$ lower, respectively) were significant. Moreover, hyphal density decreased at increasing soil depths under different treatment conditions.

Two-way analysis of variance (Fig. 2) revealed that fertilizing with extremely high or low $\mathrm{P}$ concentrations was not conducive to cotton root elongation, with maximum root lengths (28 $\left.\mathrm{m} \mathrm{plant}^{-1}\right)$ obtained under the P0.2 treatment. Furthermore, hyphal density increased with decreasing $\mathrm{P}$ content, with an average hyphal density of $12.9 \mathrm{mg}^{-1}$ following the P0 treatment. In contrast, the hyphal densities after the P0.2 and P1 treatments were 7 and $12.3 \%$ lower at 12 and $11.3 \mathrm{~m} \mathrm{~g}^{-1}$, respectively. 


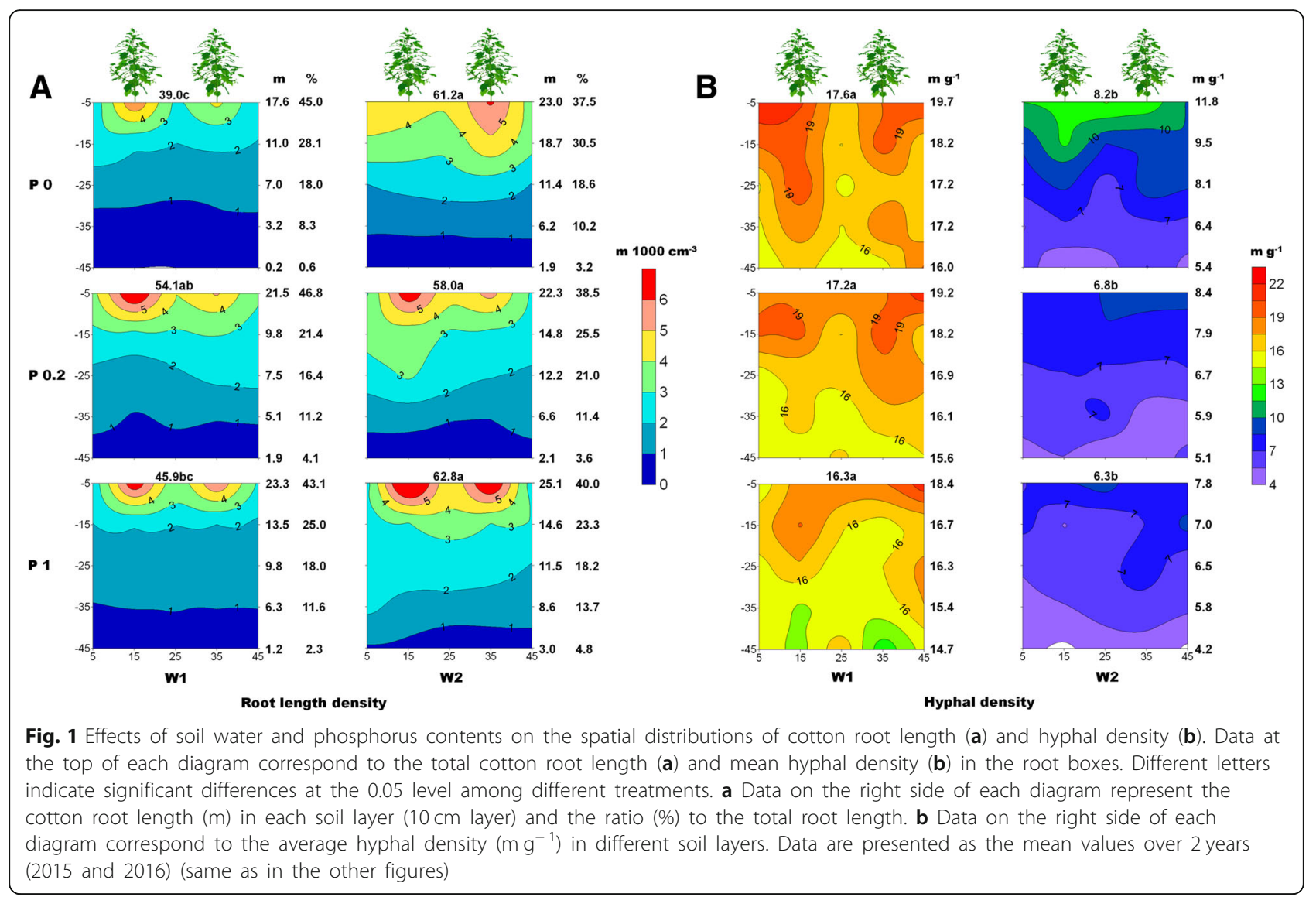

Soil water had a greater effect on cotton root and hyphal growth than $\mathrm{P}$ content. For example,, cotton root length and hyphal density were $23.2 \mathrm{~m}_{\text {plant }}{ }^{-1}$ and $7.1 \mathrm{mg}^{-1}$ under W2 conditions, while they were $30.3 \mathrm{~m} \mathrm{plant}^{-1}$ and $17.06 \mathrm{~m} \mathrm{~g}^{-1}$ under W1 conditions, respectively (i.e., increased by $30.6 \%$ and 2.4 times).
The root length differences at 30 days after sowing were mainly due to the different $\mathrm{P}$ fertilizers applied during sowing, with high $\mathrm{P}$ concentrations inhibiting root elongation (Fig. 3). Cotton root lengths induced by $\mathrm{P}$ fertilizer applications were dependent on water content over time, and the P0.2 treatment promoted root
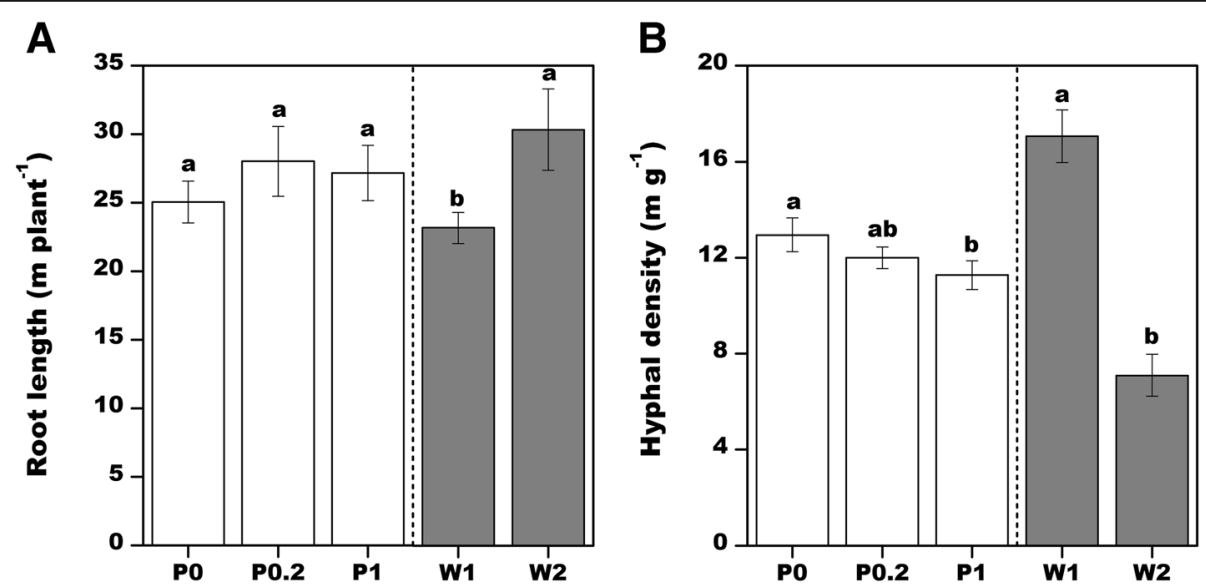

Fig. 2 Effects of different soil phosphorus and water contents on cotton root length and hyphal density (two factor analysis of variance). Different letters above bars indicate significant differences in the phosphorus (white column) or water (gray column) contents at the 0.05 level. Error bars represent the standard error of the mean $(n=6)$ (same as in Fig. 3) 


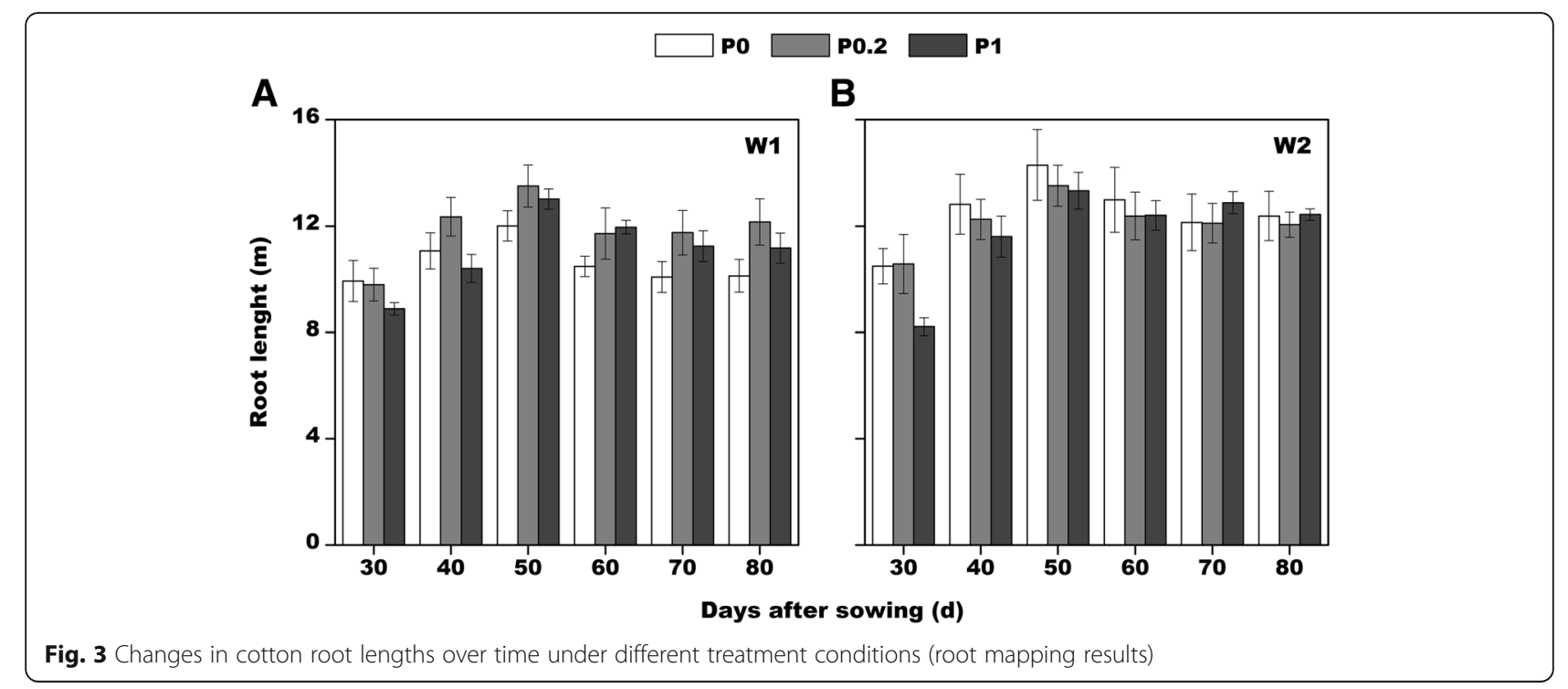

elongation under W1 conditions starting from 40 days after sowing. Under W2 conditions, the influence of different $\mathrm{P}$ fertilizers on cotton root lengths exhibited a gradually decreasing trend as the water-treatment time increased, with almost no differences at the end of the study period (80 days after sowing).

A synergistic relationship was observed between root length density and hyphal density (Fig. 4). The root length density was $0-5 \mathrm{~m} 1000 \mathrm{~cm}^{-3}$. Meanwhile, the hyphal density increased with increasing root length density, and then tended to stabilize before finally declining at root length densities $>5 \mathrm{~m} 1000 \mathrm{~cm}^{-3}$. Considering hyphal growth depends on the photosynthetic products supplied by the cotton plants, root growth is a critical factor affecting the growth of AMF associated with cotton.

\section{Cotton growth and phosphorus uptake}

Cotton root growth was relatively high under P-deficient and/or water-limited conditions (Table 1). However, shoots grew best in response to the P0.2 and

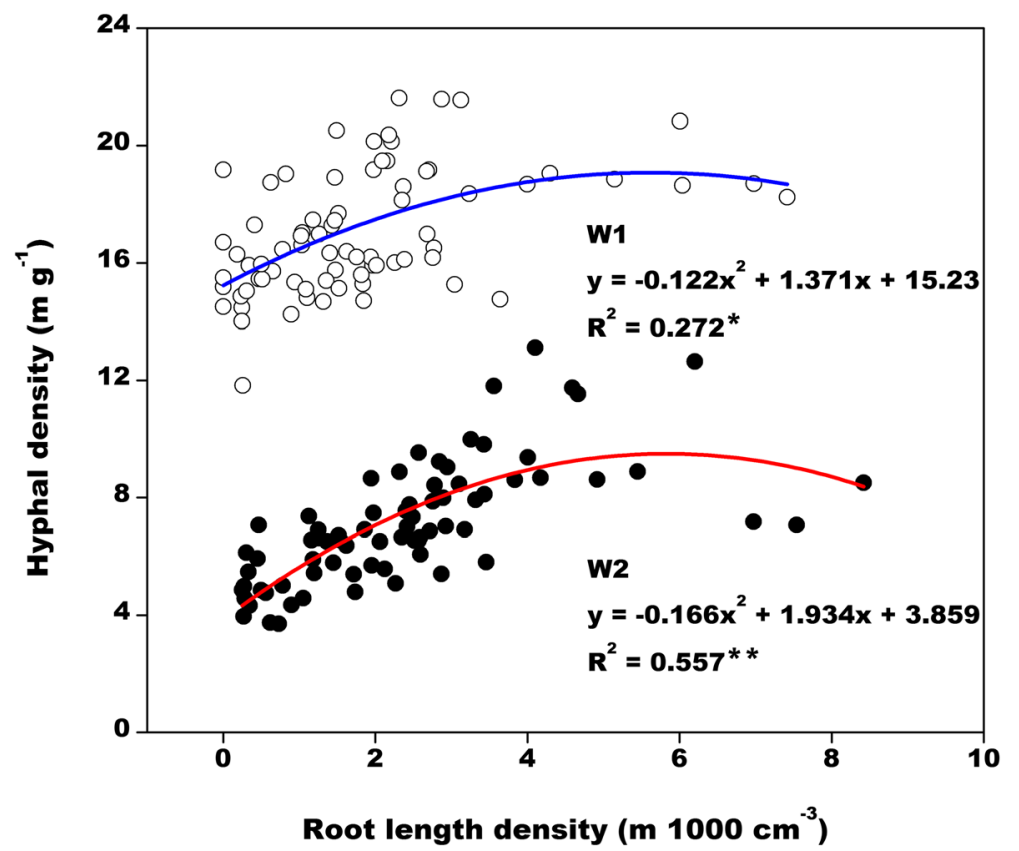

Fig. 4 Correlation between root length density and hyphal density under different soil water conditions. ** and * indicate a significant difference at the 0.01 and 0.05 levels, respectively $\left(n=75 ; P_{0.05}=0.226\right.$ and $\left.P_{0.01}=0.294\right)$ 
Table 1 Effects of soil water and phosphorus contents on the growth and phosphorus uptake of cotton plants

\begin{tabular}{|c|c|c|c|c|c|c|c|c|c|c|}
\hline \multirow[t]{2}{*}{ Treatment } & \multicolumn{5}{|c|}{ Dry matter weight (g plant ${ }^{-1}$ ) } & \multicolumn{5}{|c|}{ P uptake $\left(\mathrm{mg} \mathrm{plant}^{-1}\right)$} \\
\hline & Root & Stem & Leaf & Shoot & Total & Root & Stem & Leaf & Shoot & Total \\
\hline \multicolumn{11}{|l|}{ PO } \\
\hline W1 & $1.7 \mathrm{bc}$ & $2.5 \mathrm{bc}$ & $4.5 c$ & $7.0 \mathrm{a}$ & $8.7 b$ & $5.6 a b$ & $7.8 \mathrm{ab}$ & $15.7 \mathrm{~b}$ & $23.4 b c$ & $29.0 b$ \\
\hline W2 & $2.3 a$ & $1.6 c$ & $4.0 \mathrm{c}$ & $5.6 b$ & $7.9 b$ & $8.0 \mathrm{a}$ & $5.6 b$ & $14.8 b$ & $20.3 c$ & $28.3 b$ \\
\hline \multicolumn{11}{|l|}{ P0.2 } \\
\hline W1 & $1.3 c$ & $2.6 a b$ & $9.1 \mathrm{a}$ & $11.7 a$ & 13.0a & $4.2 \mathrm{~b}$ & $8.8 a b$ & $32.4 a$ & $41.1 \mathrm{a}$ & $45.4 a$ \\
\hline W2 & $1.6 \mathrm{bc}$ & $3.5 \mathrm{a}$ & $6.3 b$ & $9.8 \mathrm{a}$ & $11.4 \mathrm{a}$ & $5.2 \mathrm{~b}$ & $10.9 a$ & $22.1 \mathrm{ab}$ & 33.0ab & $38.3 a b$ \\
\hline \multicolumn{11}{|l|}{ P1 } \\
\hline W1 & $1.3 c$ & $2.7 a b$ & $7.2 \mathrm{~b}$ & 10.0a & $11.3 a$ & $5.7 a b$ & $9.9 a$ & $31.6 a$ & 41.6a & 47.3a \\
\hline W2 & 2.0ab & $2.3 b c$ & $4.5 c$ & $6.8 \mathrm{~b}$ & $8.8 \mathrm{~b}$ & $8.1 \mathrm{a}$ & $9.8 a$ & 21.7ab & 31.5abc & $39.7 a b$ \\
\hline
\end{tabular}

Differences among six treatments were analyzed by 2 (Water) $\times 3(\mathrm{P})$ ANOVA. Different letters within the same column indicate significant differences at the 0.05 level. "Shoot" indicates the cotton dry matter weight or $\mathrm{P}$ uptake of the stem plus leaf, and "Total" indicates the root plus shoot

well-watered conditions. Similar results were observed for P uptake.

A correlation analysis indicated that a root length of 28 $\mathrm{m}$ plant ${ }^{-1}$ and a hyphal density of $14 \mathrm{~m} \mathrm{~g}^{-1}$ were critical values for the uptake of $\mathrm{P}$ by cotton plants (Fig. 5). At lower values, $\mathrm{P}$ uptake increased with increasing root length or hyphal density, whereas higher values were associated with inhibited P uptake. Although the correlations were not significant, root length had a greater effect on $\mathrm{P}$ uptake $\left(R^{2}=0.306\right)$ than hyphal density $\left(R^{2}=0.122\right)$.

\section{Regulation of soil water and phosphorus contents}

The relationships between soil water- $\mathrm{P}$ contents and root length density, hyphal density, and P uptake by cotton plants were analyzed to determine the ideal soil water and $\mathrm{P}$ content range that can promote cotton root and hyphal growth and simultaneously maximize $\mathrm{P}$ uptake (Fig. 6). Different soil water and P contents were required for maximizing root length density, hyphal density, and $\mathrm{P}$ uptake. The optimal soil $\mathrm{P}$ and water contents were $13-25 \mathrm{mg} \mathrm{kg}^{-1}$ and $<23 \%$ for maximal cotton root elongation. In contrast, hyphal growth was highest when soil $P$ and water contents were $12-24 \mathrm{mg} \mathrm{kg}^{-1}$ and 20-30\%, respectively. Furthermore, P uptake was optimal at soil $\mathrm{P}$ and water contents of $22-37 \mathrm{mg} \mathrm{kg}^{-1}$ and $18-24 \%$, respectively.

An analysis of the combined effects of soil water and P concentrations on root length density, hyphal density, and $\mathrm{P}$ uptake (Fig. 7) revealed the optimal soil $\mathrm{P}$ and water contents for simultaneously maximizing these three main indicators were $20-25 \mathrm{mg} \mathrm{kg}^{-1}$ and $19-24 \%$, respectively.

\section{Discussion}

Soil water had more significant effects on root and hyphal growth than phosphorus levels

Drought stress increased cotton root length (Fig. 2a), while the effects of $\mathrm{P}$ on cotton root length depended on the soil water condition (P0.2 promoted root elongation in well-watered soil, while the application of P had almost no influence on root length under drought conditions). Regarding the effect of $\mathrm{P}$ fertilizer on mycorrhizal

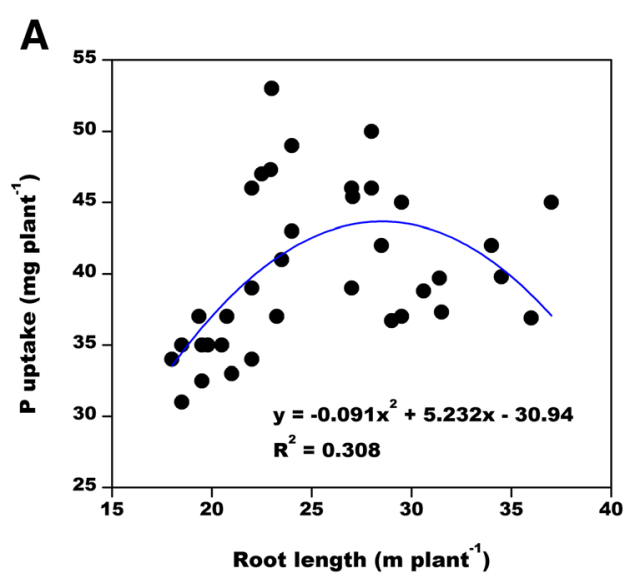

B

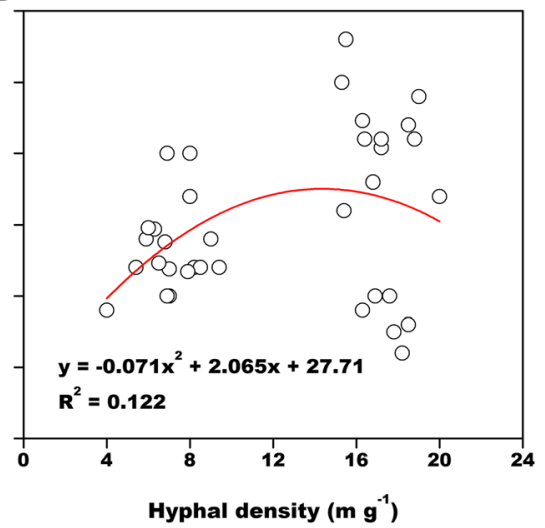

Fig. 5 Correlation between root length (a) or hyphal density (b) and uptake of phosphorus by cotton plants $(n=36)$ 


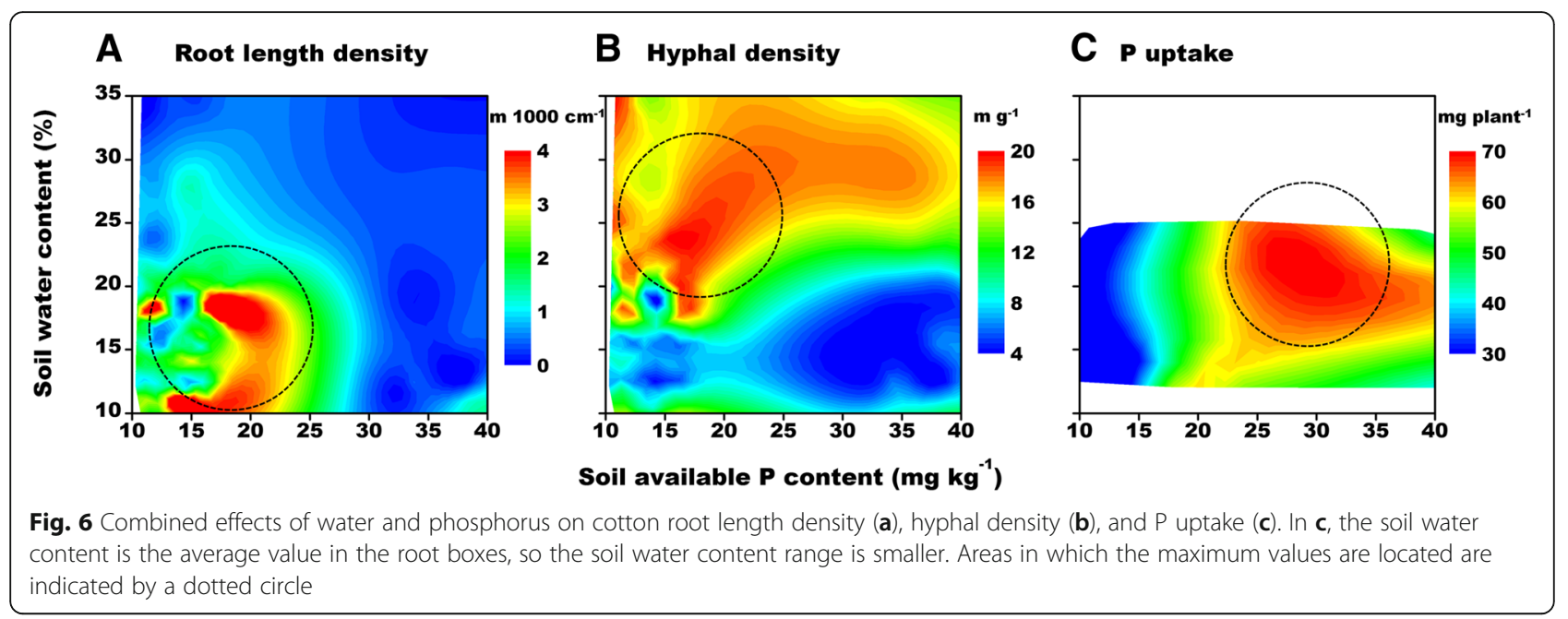

growth, a common view is that mycorrhizal colonization and growth is inhibited with increasing P levels [16]. We also observed that hyphal density gradually decreased with increasing $\mathrm{P}$ concentrations. However, the soil water condition affected hyphal growth more than the applied P, with a relatively high hyphal density in well-watered soil. The water content decreased at increasing soil depths under two water treatments, and the water content in the soil profile is obviously higher under well-watered conditions than that in water-limited conditions (Additional file 1: Figure S1) also prove this result. Several studies have confirmed that soil water conditions considerably influence plant and mycorrhizal growth. For example, Ryan and Ash [30] compared wheat growth in a field under normal conditions with wheat growth in the subsequent very dry year in southern New South Wales, Australia. They observed that mycorrhizal colonization decreased from 40 to $70 \%$ to $5-16 \%$ during the dry year. Moreover, the colonization of field-grown wheat [30] and pot-grown maize [27] by

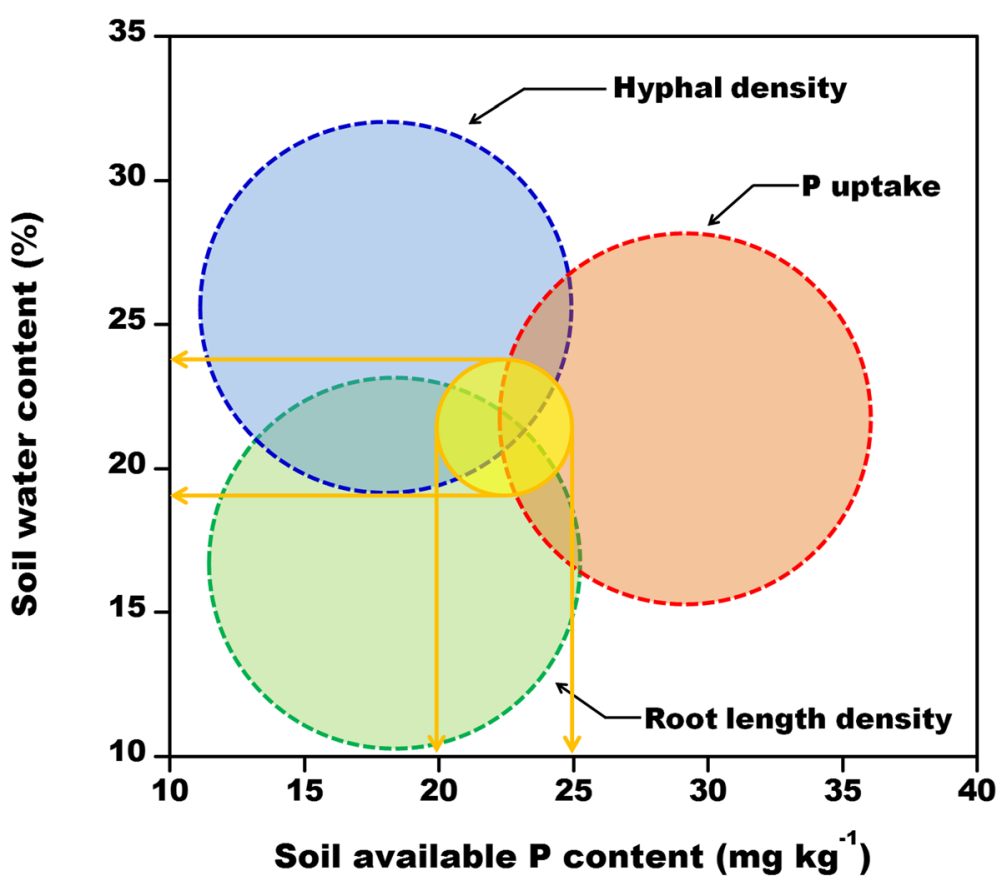

Fig. 7 Regulation of soil water and phosphorus levels on the uptake of phosphorus by cotton plants. The positions of the different colored circles are the same as in Fig. 6, and correspond to the regions with the highest values for hyphal density (blue), P uptake (red), and root length density (green) under different soil water-phosphorus conditions. The yellow circle represents the overlapping area of the three larger circles, and corresponds to the conditions for simultaneously maximizing root length, hyphal growth, and P uptake 
AMF was low under severe drought conditions. The results of another study indicated that substantial AMF colonization can occur under well-watered and mild to moderate drought conditions [31], but it is important to note that in these experiments, plants were not exposed to extreme drought stress. Thus, our data imply that prolonged severe drought conditions seriously inhibit mycorrhizal growth. Consequently, ensuring the availability of an adequate water supply is a prerequisite for $\mathrm{P}$ fertilizer-regulated cotton root and mycorrhizal growth.

Soil water levels had the opposite effects on total cotton root length and average soil hyphal density, with well-watered soil decreasing root length, but increasing hyphal density. Moreover, root length and average hyphal density did not exhibit the same trends in response to P fertilizers (Fig. 2). However, in a certain root length density range $\left(<5 \mathrm{~m} 1000 \mathrm{~cm}^{-3}\right)$, the hyphal density increased with increasing root length density (Fig. 4; potentially under well-watered conditions). Additionally, hyphal density will exhibit a decreasing trend only when the root length density increases further (probably under drought conditions). Therefore, regarding the whole soil profile, there exists a suitable water-P range that simultaneously promotes the growth of cotton roots and hyphae. For example, for cotton plants exposed to P0.2 and $\mathrm{W} 1$, root length and average hyphal density were relatively high following all treatments (Fig. 2).

\section{Optimizing phosphorus inputs and soil water can increase cotton growth and phosphorus uptake by maximizing the efficiency of phosphorus acquisition by roots/mycorrhizae}

Despite the fact drought stress promoted cotton root elongation (Fig. 2), which is theoretically conducive to the absorption of $\mathrm{P}$, the cotton shoot $\mathrm{P}$ content was lower under drought conditions than under well-watered conditions (Table 1). Furthermore, the shoot P level was highest in plants exposed to W1 and P0.2 (Table 1). The correlation analysis revealed that cotton $\mathrm{P}$ uptake increased as the roots lengthened to about $28 \mathrm{~m}_{\text {plant }}{ }^{-1}$ (Fig. 5). Longer root lengths resulted in decreased P uptake. This observation is consistent with the changes in cotton root length induced by $\mathrm{P}$ fertilizer under well-watered, but not drought, conditions. Therefore, $\mathrm{P}$ fertilizer-induced changes to roots that increase the absorption of $\mathrm{P}$ occurs only in well-watered soil. In drought-stressed cotton plants, the first adaptive response involves transferring photosynthates from the shoot to the roots, resulting in increased root growth, which enhances the ability of plants to absorb water. A consequence of these changes is that shoot growth is inhibited (Table 1).

Well-watered soil promotes hyphal growth and increases $\mathrm{P}$ uptake by cotton plants. However, increasing the $\mathrm{P}$ concentration of fertilizers suppresses hyphal growth, while increasing $\mathrm{P}$ uptake. Although hyphal density and cotton P uptake are not correlated (Fig. 5b), hyphal growth is beneficial for cotton P levels. Earlier studies confirmed that AMF increase P uptake by cowpea and capsicum only under drought and P-deficient conditions [31, 32]. Similarly, in numerous other species, $P$ levels are enhanced in AMF-colonized plants under drought conditions, which many authors have suggested is responsible for increasing drought resistance [25, 26, 33-35]. However, it is important to note that these experiments involved only mild-moderate drought stress. In contrast, in the present study, plants were exposed to more severe drought conditions over a longer period, which inhibited the growth of mycorrhizal fungi and decreased the contribution of the AMF P-uptake pathway. We did not use moderate or mild drought treatments. Our justification for this is that in contrast to the aforementioned studies in which increased P uptake via AMF colonization improved drought resistance, the uptake of $\mathrm{P}$ after exposing perennial ryegrass and wheat to drought stress is reportedly unaffected by the presence of AMF $[28,29]$. Similarly, inoculations with AMF did not affect maize growth under drought conditions [27].

Although there is some inconsistency in hyphal and root growth responses to water-P contents, it is still important to consider the overall effects of different water and $\mathrm{P}$ levels on root elongation, hyphal growth, $\mathrm{P}$ uptake, cotton growth, and even nutrient input costs. A combination of W1 and P0.2 conditions maximizes root and mycorrhizal development, thereby ensuring improved cotton growth and increased $\mathrm{P}$ uptake. Under the conditions tested during this study, the ideal soil water and available P contents were $19-24 \%$ and $20-25$ $\mathrm{mg} \mathrm{kg}^{-1}$, respectively (Fig. 7). To further quantify the effects of different water and $\mathrm{P}$ conditions on AMF and $\mathrm{P}$ uptake by cotton roots, it is very important that the contributions of the direct root P-uptake and AMF P-uptake pathways following different water and $\mathrm{P}$ treatments are determined.

\section{Conclusions}

Drought stress inhibited hyphal growth compared with well-watered condition. Additionally, P fertilizer-regulated cotton root elongation occurred only under well-watered conditions. Too much or too little $\mathrm{P}$ fertilizer inhibited cotton root elongation. In contrast, root elongation was essentially unaffected by P fertilizers under drought conditions. The effects of $\mathrm{P}$ on hyphal growth exhibited a similar trend regardless of soil water conditions (i.e., hyphal density decreased as P content increased). Under well-watered conditions, the application of $\mathrm{P}$ fertilizers significantly increased cotton $\mathrm{P}$ uptake, but there was no significant difference between the 
P0.2 and P1 treatments. Therefore, there is some inconsistency in root and hyphal growth as well as cotton $\mathrm{P}$ uptake in response to soil water-P changes. Therefore, the soil water-P contents (i.e., soil water and P contents of $19-24 \%$ and $20-25 \mathrm{mg} \mathrm{kg}^{-1}$, respectively) should be controlled to simultaneously maximize cotton root/ mycorrhizal growth and P uptake by cotton plants.

\section{Methods}

\section{Biological materials and soil}

Seeds of Gossypium hirsutumcv. XLZ50, which is currently the major cultivated cotton genotype in Xinjiang, were obtained from the Xinjiang Academy of Agricultural Sciences, China. Cotton plants were grown in a gray desert soil collected from the Xiaoguai Experimental Station of the Xinjiang Institute of Ecology and Geography, Chinese Academy of Sciences in Urumqi, China. The soil collected from a field that had not been used to grow crops was air-dried and then filtered through a 2-mm sieve. An analysis prior to sowing revealed the soil chemical properties were as follows: $16.7 \mathrm{mg} \mathrm{kg}^{-1} \mathrm{ex}-$ tracted mineral nitrogen, $\mathrm{pH}\left(\mathrm{H}^{2} \mathrm{O}\right) 8.1,1.33 \mathrm{~g} \mathrm{~cm}^{-3}$ soil density, 8.2 mgkg $^{-1}$ Olsen-P, $208.9 \mathrm{mg} \mathrm{kg}^{-1} \mathrm{NH}_{4} \mathrm{OA}-$ c-extracted potassium, and $5.3 \mathrm{~g} \mathrm{~kg}^{-1}$ organic matter.

\section{Experimental design}

This study was conducted in a greenhouse over 90 days from June to September in 2015 and 2016. Experiments comprised two water contents and three P contents in a $2 \times 3$ factorial design. The two water contents were $80 \%$ of field water capacity (W1, well-watered) and $40 \%$ of field water capacity (W2, drought). The three P contents were $0 \mathrm{~g} \mathrm{P}_{2} \mathrm{O}_{5} \mathrm{~kg}^{-1}$ (P-deficient, P0), $0.2 \mathrm{~g} \mathrm{P}_{2} \mathrm{O}_{5} \mathrm{~kg}^{-1}$ (middling $\mathrm{P}, \mathrm{P} 0.2$ ), and $1 \mathrm{~g}_{2} \mathrm{O}_{5} \mathrm{~kg}^{-1}$ (excess $\mathrm{P}, \mathrm{P} 1$ ). Three replicates were analyzed for each of the six treatment combinations.

Soil (38 kg) was weighed in a plastic bag and then thoroughly mixed with $\mathrm{KH}_{2} \mathrm{PO}_{4}\left(0,0.2\right.$, or $\left.1 \mathrm{~g} \mathrm{P}_{2} \mathrm{O}_{5} \mathrm{~kg}^{-1}\right)$ and urea $\left(0.25 \mathrm{~kg} \mathrm{~N} \mathrm{~kg}^{-1}\right)$ before being added to glass root boxes (width and height: $60 \mathrm{~cm}$; thickness: $10 \mathrm{~cm}$ ) (Fig. 8). The root boxes were divided into three groups with each being filled with $0.2 \mathrm{~g} \mathrm{P}_{2} \mathrm{O}_{5} \mathrm{~kg}^{-1} \mathrm{P}$ fertilizer, $1 \mathrm{~g} \mathrm{P}_{2} \mathrm{O}_{5} \mathrm{~kg}^{-1}$ $\mathrm{P}$ fertilizer, or no $\mathrm{P}$ fertilizer.

Cotton seeds were disinfected with $10 \%(v / v) \mathrm{H}_{2} \mathrm{O}_{2}$ for $10 \mathrm{~min}$ and $70 \%(\mathrm{v} / \mathrm{v})$ ethanol for $3 \mathrm{~min}$ and then rinsed

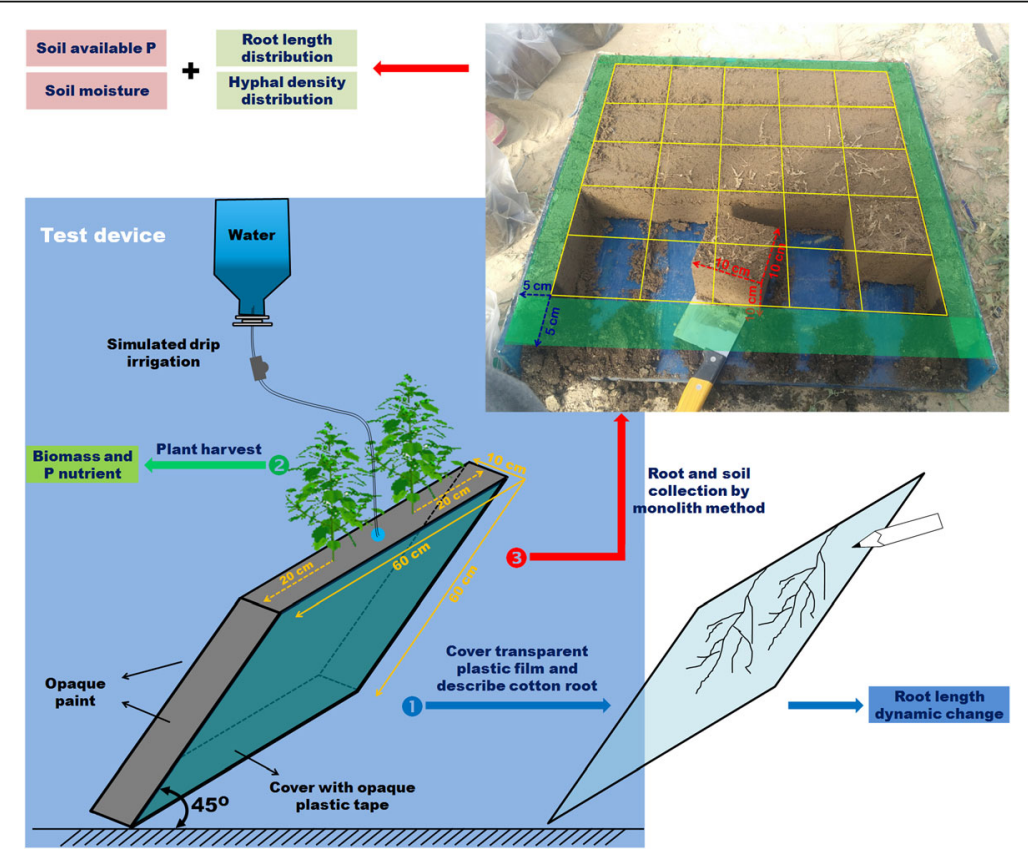

Fig. 8 Root box specifications and diagram of the cotton cultivation method. Root boxes were made of 8-mm thick glass (length and width: 60 $\mathrm{cm}$; internal thickness: $10 \mathrm{~cm}$ ), with an opening on top for planting cotton. Four sides of each root box were covered with opaque paint, and the remaining side $(60 \mathrm{~cm} \times 60 \mathrm{~cm})$ was covered with opaque plastic, which was removed to observe the root morphology. The root boxes were maintained at a $45^{\circ}$ angle between this side and the ground to ensure the cotton roots will grow close to the glass wall. Each root box consisted of two cotton plants separated by $20 \mathrm{~cm}$. A drip irrigation system was simulated to accurately control the flow of water. During the experiment, the opaque plastic was removed and replaced with a transparent plastic film, after which the cotton root architecture was traced using a black marker and then scanned to quantify the root length changes $(\mathbf{(})$. At the end of the experiment, the shoots were harvested, additionally, to examine cotton growth and Puptake (2). The soil in each root box was cut into cubes with $10-\mathrm{cm}$ sides (25 blocks per root box). The roots were collected after the soil samples were passed through a sieve for root length measurements, while the soil samples were collected for determining hyphal density, soil water level, and available P content (3) 
eight times with sterile deionized water. After a 2-day imbibition in water at $27^{\circ} \mathrm{C}$ in darkness, six pre-germinated seeds were sown in pots. The plants were thinned to two seedlings per pot after 10 days. Soil water was maintained at $80 \%$ of field water capacity as determined gravimetrically by weighing the pots every 3 days and adding water as necessary with a simulated drip irrigation system. Water treatments were initiated 30 days after sowing, with root boxes for each P fertilizer treatment divided into two groups. For the remainder of the experiment, the soil water level of half of the root boxes was kept at $80 \%$ of field water capacity, while the soil water content of the other half was lowered to $40 \%$ of field water capacity.

\section{Sample harvest and analysis}

The root systems were analyzed when initiating the water treatments and then re-analyzed every 10 days for 60 days (six times in total) (Fig. 81). The roots were then scanned with a digital scanner (Epson V700, Djakarta, Indonesia) at $200 \mathrm{dpi}$ with grayscale pixels. The resulting images were saved as TIF files and then analyzed using the DELTA-T SCAN program (version 1.0) (Delta-T Devices, Burwell, UK).

At the end of the 60-day water treatments, the shoots were cut and divided into leaves and stems (Fig. 82). All samples were heated at $105^{\circ} \mathrm{C}$ for $30 \mathrm{~min}$ and then dried at $70{ }^{\circ} \mathrm{C}$ until a constant weight was attained. The dry weight was recorded and subsamples were used to measure the $\mathrm{P}$ content according to the standard vanado-molybdate method [36].

After harvesting the shoots, the roots were collected using a published monolith method [37] (Fig. 83). Soil cubes with $10 \mathrm{~cm}$ sides $\left(1000 \mathrm{~cm}^{3}\right)$ were cut individually in a soil volume of $50 \mathrm{~cm} \times 50 \mathrm{~cm} \times 10 \mathrm{~cm}$. The 25 monoliths prepared for each root box were sieved through a stainless steel mesh (1 mm diameter) and the roots were rinsed with water. The collected samples were then stored at $-20^{\circ} \mathrm{C}$ until the root lengths were measured.

Soil samples were collected from each soil block after the roots were sieved, with some being used to measure soil water content according to a drying method, while others were air-dried and passed through a sieve $(1 \mathrm{~mm}$ diameter) and analyzed. The available $\mathrm{P}$ was extracted from soil using $0.5 \mathrm{M} \mathrm{NaHCO}_{3}$ (2.5 g soil in a $50-\mathrm{ml}$ solution shaken at $25^{\circ} \mathrm{C}$ for $30 \mathrm{~min}$ ) and the inorganic $\mathrm{P}$ was colorimetrically measured using an established molybdate-ascorbic acid method [38]. The hyphal density in the soil was measured using a modified membrane filter technique [39].

Roots collected from each soil block were also analyzed with a digital scanner. Root samples were placed in a glass rectangular dish $(200 \mathrm{~mm} \times 150 \mathrm{~mm})$ containing a 4-5-mm layer of water to untangle the roots and minimize root overlap. When necessary, the roots of one soil block were separated into subsamples until they could be placed in the dish. The images were analyzed using the DELTA-T SCAN program. The root fractions were subsequently combined and dried at $70{ }^{\circ} \mathrm{C}$ until a constant weight was attained. Sample weight and P content were then recorded.

\section{Data analysis}

Data underwent a 2-way analysis of variance (SAS 8.0 software, SAS Institute, 1998). Means in the different treatments were compared based on the least significant difference at the 0.05 level of significance. The spatial distributions of cotton root length density and hyphal density in the soil profiles are presented as wireframe diagrams (Surfer 9.0 software). The mean root length per plant ( $\mathrm{m}$ plant ${ }^{-1}$ ) was calculated by dividing the total root length for the 25 soil blocks by 2 (i.e., the number of sampled plants).

\section{Additional file}

Additional file 1: Figure S1. Soil water content under different water treatment. (TIF $692 \mathrm{~kb}$ )

Abbreviations

AMF: Arbuscular mycorrhizal fungi; DAS: Days after sowing

Acknowledgments

We thank Liwen Bianji, Edanz Editing China (www.liwenbianji.cn/ac) for editing the English text of a draft of this manuscript.

\section{Funding}

This study was supported by the National Natural Science Foundation of China (U1403285). Authors declare that none of the funding bodies have any role in the design of the study and collection, analysis, and interpretation of data as well as in writing the manuscript.

Availability of data and materials

The datasets used and/or analysed during the current study available from the corresponding author on reasonable request.

Authors' contributions

MWX, TCY and FG designed the research, MWX wrote the article. XXR cultivated the cotton plants. All authors read and approved the final manuscript.

Ethics approval and consent to participate Not applicable.

Consent for publication

Not applicable.

Competing interests

The authors declare that they have no competing interests.

\section{Publisher's Note}

Springer Nature remains neutral with regard to jurisdictional claims in published maps and institutional affiliations. 


\section{Author details}

'Xinjiang Institute of Ecology and Geography, Chinese Academy of Sciences, Urumqi 830011, China. ${ }^{2}$ State Key Laboratory of Oasis Ecology and Desert Environment, Urumai 830011, China. ${ }^{3}$ College of Resources and Environment, China Agricultural University, Beijing 100083, China. ${ }^{4}$ Changji National Agricultural Science and Technology Park, Changji 831100, China.

Received: 23 August 2018 Accepted: 21 November 2018

Published online: 05 December 2018

\section{References}

1. Zhang FS, Shen JB, Zhang JL, Zuo YM, Li L, Chen XP. Rhizosphere processes and management for improving nutrient use efficiency and crop productivity: implications for China. Adv Agron. 2010;107:1-32.

2. Li HG, Huang G, Meng Q, Ma L, Yuan LX, Wang F, Zhang W, Cui ZL, Shen JB, Chen XP, Jiang RF, Zhang FS. Integrated soil and plant phosphorus management for crop and environment in China. A review. Plant Soil. 2011; 349:1-11.

3. Zhang FS, Wang JQ, Zhang WF, Cui ZL, Ma WQ, Chen XP, Jiang RF. Nutrient use efficiencies of major cereal crops in China and measures for improvement. Acta Pedol Sin. 2008;45(5):915-24.

4. Smith SE, Jakobsen I, Grønlund M, Smith FA. Roles of arbuscular mycorrhizas in plant phosphorus nutrition: interactions between pathways of phosphorus uptake in arbuscular mycorrhizal roots have important implications for understanding and manipulating plant phosphorus acquisition. Plant Physiol. 2011;156:1050-7.

5. Smith SE, Smith FA, Jokobsen I. Mycorrhizal fungi can dominate phosphate supply to plants irrespective of growth responses. Plant Physiol. 2003;133:16-20.

6. Yang LT, Jiang HX, Qi YP, Chen LS. Differential expression of genes involved in alternative glycolytic pathways, phosphorus scavenging and recycling in response to aluminum and phosphorus interactions in Citrus roots. Mol Biol Rep. 2012;39(5):6353-66.

7. Yang LT, Jiang HX, Tang N, Chen LS. Mechanisms of aluminum-tolerance in two species of citrus: secretion of organic acid anions and immobilization of aluminum by phosphorus in roots. Plant Sci. 2011;180:521-30.

8. Schachtman DP, Reid RJ, Ayling SM. Phosphorus uptake by plants: from soil to cell. Plant Physiol. 1998;116:447-53.

9. Lin ZH, Chen LS, Chen RB, Zhang FZ, Jiang HX, Tang N, Smith BR. Root release and metabolism of organic acids in tea plants in response to phosphorus supply. J Plant Physiol. 2011;168:644-52.

10. Lin ZH, Chen LS, Chen RB, Zhang FZ, Yang LT, Tang N. Expression of genes for two phosphofructokinases, tonoplast ATPase subunit a, and pyrophosphatase of tea roots in response to phosphorus-deficiency. J Hortic Sci Biotechnol. 2010;85(5):449-53.

11. Chen LS, Yang LT, Lin ZH, Tang N. Roles of organic acid metabolism in plant tolerance to phosphorus-deficiency. Prog Bot. 2013;74:213-37.

12. Lynch JP, Ho MD. Rhizoeconomics: carbon costs of phosphorus acquisition. Plant Soil. 2005;269:45-56.

13. Liao H, Ge ZY, Yan XL. Ideal root architecture for phosphorus acquisition of plants under water and phosphorus coupled stresses: from simulation to application. Chin Sci Bull. 2001:46(16):34-78.

14. Liao H, Rubio G, Yan X, Cao A, Brown K, Lynch JP. Effect of phosphorus availability on basal root shallowness in common bean. Plant Soil. 2001; 232:69-79.

15. Liao H, Yan X, Rubio G, Beebe S, Blair MW, Lynch JP. Genetic mapping of basal root gravitropism and phosphorus acquisition efficiency in common bean. Func Plant Biol. 2004;31:959-70.

16. Lekberg Y, Koide RT. Is plant performance limited by abundance of arbuscular mycorrhizal fungi ? A meta-analysis of studies published between 1988 and 2003. New Phytol. 2005;168:189-204.

17. Liu W, Zheng CY, Fu ZF, Gai JP, Zhang JL, Christie P, Li XL. Facilitation of seedling growth and nutrient uptake by indigenous arbuscular mycorrhizal fungi in intensive agroecosytems. Biol Fert Soil. 2014;50:381-94.

18. Chu Q. Contribution of mycorrhizal pathway to phosphorus uptake efficiency in maize. Beijing: Doctoral Dissertation of China Agricultural University; 2013

19. Lynch JP. Root phenes for enhanced soil exploration and phosphorus acquisition: tools for future crops. Plant Physiol. 2011;156:1041-9.

20. Doerner P. Phosphate starvation signaling: a threesome controls systemic P(i) homeostasis. Curr Opin Plant Biol. 2008;11:536-40.
21. López-Bucio J, Cruz-Ramírez A, Herrera-Estrella L. The role of nutrient availability in regulating root architecture. Curr Opin Plant Biol. 2003;6:280-7.

22. Wang YS, Thorup-Kristensen K, Jensen LS, Magid J. Vigorous root growth is a better indicator of early nutrient uptake than root hair traits in spring wheat grown under low fertility. Front Plant Sci. 2016;7:865.

23. Mai WX, Tian CY, Li CJ. Above- and belowground growth responses in cotton to drip irrigation under mulch film. Aus J Soil Res. 2012;6(5):946-51.

24. Suriyagoda LDB, Ryan $M H$, Renton $M$, Lambers $H$. Plant responses to limited moisture and phosphorus availability: a meta-analysis. Adv Agron. 2014;124:143-200

25. Maiquetia M, Caceres A, Herrera A. Mycorrhization and phosphorus nutrition affect water relations and CAM induction by drought in seedlings of Clusia minor. Ann Bot. 2009;103:525-32.

26. Neumann E, George E. Colonisation with the arbuscular mycorrhizal fungus Glomus mosseae (Nicol. \& Gerd.) enhanced phosphorus uptake from dry soil in Sorghum bicolor (L.). Plant Soil. 2004;261:245-55.

27. Hetrick BAD, Kitt DG, Wilson GT. Effects of drought stress on growth response in corn, Sudan grass, and big bluestem to Glomus etunicatum. New Phytol. 1987;105:403-10.

28. Bryla DR, Duniway JM. Growth, phosphorus uptake, and water relations of safflower and wheat infected with an arbuscular mycorrhizal fungus. New Phytol. 1997:136:581-90.

29. Jupp AP, Newman El. Phosphorus uptake from soil by Lolium perenne during and after severe drought. J Appl Ecol. 1987;24:979-90.

30. Ryan MH, Ash J. Colonisation of wheat in southern New South Wales by vesicular-arbuscular mycorrhizal fungi is significantly reduced by drought. Aust J Exp Agric. 1996;36:563-9.

31. Kwapata MB, Hall AE. Effects of moisture regime and phosphorus on mycorrhizal infection, nutrient uptake, and growth of cowpeas (Vigna unguiculata (L.) Walp.). Field Crop Res. 1985;12:241-50.

32. Waterer D, Coltman R. Response of lettuce to pre- and post-transplant phosphorus and pre-transplant inoculation with a VA-mycorrhizal fungus. Plant Soil. 1989:117:151-6.

33. El-Tohamy W, Schnitzler WH, El-Behairy U, El-Betag MS. Effect of VA mycorrhiza on improving drought and chilling tolerance of bean plants. J Appl Bot. 1999;73:178-83.

34. Goicoechea N, Antolín MC, Sánchez-Díaz M. Influence of arbuscular mycorrhizae and rhizobium on nutrient content and water relations in drought stressed alfalfa. Plant Soil. 1997;192:261-8.

35. Von Reichenbach HG, Schonbeck F. Influence of VA-mycorrhiza on drought tolerance of flax (Linum usitatissimum L). 2. Effect of VA-mycorrhiza on stomatal gas exchange, shoot water potential, phosphorus nutrition and the accumulation of stress metabolites. J Appl Bot. 1995;69:183-8.

36. Bao SD. Analysis of agricultural chemistry in soil. Beijing: Chinese Agricultural Press; 1999.

37. Böhm W. Methods of studying root systems. Berlin: Springer-Verlag; 1979.

38. Murphy J, Rile JP. A modified single solution method for the determination of phosphate in natural waters. Anal Chim Acta. 1962;27:31-6.

39. Jakobsen I, Abbott LK, Robson AD. External hyphae of vesicular-arbuscular mycorrhizal fungi associated with Trifolium subterraneum L. 1. Spread of hyphae and phosphorus inflow into roots. New Phytol. 1992;120:371-80.

Ready to submit your research? Choose BMC and benefit from:

- fast, convenient online submission

- thorough peer review by experienced researchers in your field

- rapid publication on acceptance

- support for research data, including large and complex data types

- gold Open Access which fosters wider collaboration and increased citations

- maximum visibility for your research: over $100 \mathrm{M}$ website views per year

At $\mathrm{BMC}$, research is always in progress.

Learn more biomedcentral.com/submissions 